\title{
É POSSÍVEL DECOLONIZAR A HISTÓRIA DA PEDAGOGIA? APRENDIZAGENS A PARTIR DA FILOSOFIA DA EDUCAÇÃO MAIA ${ }^{i}$
}

\author{
Maria Teresa Muraca ${ }^{\text {ii }}$
}

\begin{abstract}
Resumo: A adesão a uma abordagem intercultural crítica exige o questionamento da própria constituição da pedagogia que, como as outras ciências humanas e sociais, é um produto da modernidade-colonialidade. Em particular, o que é habitualmente transmitido como História da pedagogia não é um saber neutro, mas um saber excludente, que seleciona apenas algumas tradições de pensamento designadas como origem e fontes de legitimação da civilização ocidental. Neste artigo serão exploradas algumas dimensões da filosofia da educação maia, no interior de um discurso que entretece passado e presente, indo e vindo do tempo da précolonialidade ao largo tempo da decolonialidade que vivenciamos hoje. Em particular, será aprofundada a concepção da interdependência cósmica, geracional e entre as espécies, com o objetivo de ampliar os horizontes epistemológicos e teóricos em favor da vida.
\end{abstract}

Palavras-chave: História da Pedagogia; Maias; Filosofia da Educação; Pensamento Decolonial; Guatemala.

\section{¿ES POSIBLE DECOLONIZAR LA HISTORIA DE LA PEDAGOGÍA? APRENDIZAJES A PARTIR DE LA FILOSOFÍA DE LA EDUCACIÓN MAYA}

Resumen: La adhesión a un enfoque intercultural crítico exige el cuestionamiento de la propia constitución del conocimiento de la pedagogía que, como las otras ciencias humanas y sociales, es un producto de la modernidad-colonialidad. En particular, lo que es habitualmente transmitido como Historia de la pedagogía no es un saber neutro, sino un saber excluyente, que selecciona sólo algunas tradiciones de pensamiento designadas como origen y fuentes de legitimación de la civilización occidental. En este artículo se explorarán algunas dimensiones de la filosofía de la educación maya, dentro de un discurso que entretece pasado y presente, yendo y venido del tiempo de la precolonialidad a lo largo tiempo de la decolonialidad que vivimos hoy. En particular, se profundizará la concepción de la interdependencia cósmica, generacional y entre las especies, con el objetivo de ampliar los horizontes epistemológicos y teóricos en favor de la vida.

Palabras clave: Historia de la Pedagogía; Mayas; Filosofía de la Educación; Pensamiento Decolonial; Guatemala. 


\section{Introdução: o que me motivou a escrever este artigo}

Neste momento de minha trajetória profissional, estou envolvida em dois compromissos principais: a escrita de um manual de pedagogia para o ensino médio e a docência universitária no âmbito da pedagogia geral e social e da história da educação. De acordo com Paulo Freire (1987), a educadora e o educador dialógico, quando ensina, refaz seu conhecimento. Assim, me encontro na situação de me perguntar: por que amo a educação e a pedagogia? Qual pedagogia quero partilhar? Com qual pedagogia estou em conflito? E, sobretudo, a partir de quais linhas de poder foi se construindo, se legitimando e se consolidando o saber pedagógico? Não é incomum nos depararmos com falas de pedagogistas do hemisfério norte insistindo na necessidade e na urgência de dotar a pedagogia de asas intercontinentais (Frabboni, 2009) para superar as cercas do nosso olhar etnocêntrico e conferir credibilidade à aposta intercultural. Mesmo assim, a história da pedagogia continua reproduzindo a macronarrativa da civilização ocidental, desde sua formação na antiga Grécia e na sua filosofia, passando para a cultura cristã até a modernidade (Mignolo, 2002). Esta história não é neutra porque aceita sem questionar as marginalizações e as exclusões implícitas na própria constituição das ciências humanas e sociais, da qual a pedagogia forma parte, enquando produtos da modernidade-colonialidade (Walsh, 2014). Este impasse não pode ser resolvido simplesmente explorando experiências educativas, precisamos abrir o saber pedagógico às provocações que procedem das filosofias da educação amadurecidas em outras latitudes. É um desafio enorme depois de tantos séculos de silenciamento, opressão e teorizações sobre a incapacidade de pensar de determinados grupos humanos e partes do mundo (Mignolo, 2002). Mas o que está em jogo é a possibilidade de sarar a humanidade de suas feridas históricas e, talvez, salvá-la do colapso iminente. Este artigo propõe algumas pinceladas de filosofia da educação maia, assim como pude aprendê-las através da participação-reflexiva junto ao Mojoca (Movimiento de Jovenes de la Calle), um movimento de jovens de rua de Ciudad de Guatemala que implicitamente retoma algumas instâncias de resistência-existência do nunca vencido povo maia; de uma convivência muito breve, mas intensa, na comunidade maia Q'eqchi “Acampamento dos”, na região do Petén, na 
Guatemala, em 2017; e de algumas leituras e amizades iluminadoras. É importante salientar todavia que a finalidade deste artigo não é oferecer uma elaboração exaustiva sobre a filosofia da educação maia - além de tudo porque a cultura maia é um mosaico atravessado por significativas diferenças internas - mas, sim, contribuir de forma muito parcial à tarefa de desconstruir-reconstruir o saber da pedagogia por meio de alternativas não europeias e não eurocêntricas. Neste sentido, tomo a liberdade de entretecer passado e presente, de ir e vir do tempo da pré-colonialidade ao largo tempo da decolonialidade que vivenciamos hoje (Walsh, 2009) e vice-versa, dialogando com alguns documentos históricos que sobreviveram à violência epistémica do colonialismo, com as traças ancestrais encarnadas no presente e com as constantes reinvenções culturais.

\section{Contextualizações históricas e políticas}

Convencionalmente, a história maia anterior à chegada dos espanhóis é dividida em três grandes períodos: o pré-clássico (de 2000 a.C. a 250 d.C.), o clássico (de 250 d.C. a 900 d.C.) e o pós-clássico (de 900 a.C. à chamada Conquista). Esta história se desenvolveu na Mesoamérica, ou Anawak, como se diz na língua nahuatl, junto com outras civilizações, como a tolteca, a olmeca e a mexica. Em particular, o território maia incluía os atuais estados do sudeste mexicano (Iucatã, Campeche, Tabasco, Quintana Roo e a parte oriental de Chiapas), a Guatemala, Belize, parte de Honduras e El Salvador. A cultura maia se formou no início do período pré-clássico, quando as aldeias agrícolas tornaram-se maiores e mais complexas, transformando-se em centros urbanos organizados hierarquicamente: a população aumentou, a agricultura virou uma atividade mais intensiva e a escrita logosilábica começou a ser usada.

O clássico é considerado o período de máximo florescimento da civilização maia: começaram a se consolidar os negócios de longa distância, ao mesmo tempo em que as guerras entre os principais centros de poder para o controle regional iam se intensificando.

A civilização maia se baseava em cidades-estado que, dependendo das circunstâncias históricas, competiam entre si, estipulavam alianças ou colonizavam outros territórios. As 
cidades maiores eram Tikal, na Guatemala, Caracol, em Belize, e Calakmul, no México. Tinham uma população de mais de 50.000 habitantes e estavam cercadas por assentamentos menores. Seguiam Copán, em Honduras, Palenque, no México, e Naranjo, na Guatemala, com uma população entre 15.000 e 25.000 pessoas. Existia, também, um grande número de centros com 10.000 habitantes ou menos. Nas cidades havia grandes prédios cívicos-cerimoniais, residências centrais e elaboradas reservadas à elite, além de casas mais simples para as pessoas comuns, geralmente localizadas nas proximidades.

No período clássico foram construídos os mais majestosos monumentos maias: pirâmides, templos, palácios com várias salas, estádios para o jogo de bola, estelas, altares esculpidos e inscrições. O uso da escrita em monumentos visava registrar eventos significativos e celebrar datas importantes na vida dos soberanos. Neste período, o conhecimento astronômico e a medição do tempo foram desenvolvidos por meio de calendários que permitiram antecipar os eventos celestes, com base nos quais eram planejados ataques, rituais e atividades da vida cotidiana. Na complexa sociedade maia clássica, a distinção nos grupos sociais se fundamentava em um conjunto de fatores econômicos, políticos, étnicos e dinásticos. É possível identificar em linhas gerais as principais posições sociais, que compreendiam a elite dominante, os nobres, os vassalos de alta, média e baixa posição social. As evidências arqueológicas atualmente disponíveis não permitem confirmar a existência de escravos.

No início do período pós-clássico se situa o evento conhecido como colapso maia: as cidades mais importantes foram abandonadas e substituídas por outros centros, a construção de grandes edifícios e as inscrições em monumentos cessaram. As estudiosas e os estudiosos colocam na origem deste evento uma convergência de causas: uma grave crise ambiental paralelamente ao aumento exponencial da população, junto à incapacidade política de lidar com as mudanças. Toda a região mesoamericana foi afetada por transformações significativas nos sistemas econômico e político, por movimentos migratórios, pela intensificação dos conflitos e a extensão do domínio méxico. No período pós-clássico, duas cidades exerceram o papel de capitais culturais: primeiro Chichén Itzá, no México - a mais cosmopolita das cidades maias - e, depois, a vizinha Mayapan. Mayapan dominou a Península de Iucatã até 
cerca de 1450. Quando os Espanhóis chegaram ali, numerosas pequenas províncias independentes eram governadas por autoridades locais. Diferentemente, na região dos planaltos guatemaltecos, os espanhóis encontraram cidades em expansão caracterizadas por um alto desenvolvimento agrícola. Algumas, como os reinos k’iche’e kaqchikel, constituíam poderosas e extensas entidades políticas. Por certo tempo, a invasão estrangeira não conseguiu penetrar na região guatemalteca do Petén, sendo que as condições geográficas a tornavam isolada e de difícil acesso. A Conquista se caracterizou por uma fase inicial muito agressiva do ponto de vista militar, na qual a superioridade militar dos espanhóis, liderados por Pedro Alvarado e com o apoio de populações inimigas, desempenhou um papel fundamental. Uma segunda fase de conquista pacífica, baseada na missão evangelizadora dos freis dominicanos e, finalmente, uma terceira e longa fase de companhas militares e tentativas de evangelização. Só em 1697 os dominadores lograram subjugar a última cidade maia independente, Itza Tayasal, em Petén, na Guatemala. Todavia, em 1761, uma nova rebelião foi liderada pelo maia Jacinto Canek.

O evento que ainda continua sendo definido como "Descoberta da América" foi realmente um dos mais violentos e dramáticos da história da humanidade. Não somente pelo genocídio que causou uma redução de mais de $80 \%$ da população do continente, mas também pela subversão do tecido social e pela repressão das visões de mundo que orientavam a vida dos povos originários (Todorov, 1987). Os europeus impuseram sua chegada como o ponto zero da história (Castro-Gómez, 2005), promovendo o cancelamento de tudo aquilo que havia antes. Infelizmente, o extermínio indígena continua até hoje. A Guatemala é o único país da América Central cuja população é composta principalmente por povos indígenas. De 1960 a 1996, o país vivenciou uma sangrenta guerra civil, associada a um terrível genocídio conduzido pelo exército nacional e por organizações paramilitares contra a população maia. $\mathrm{O}$ único propósito era de perpetuar os privilégios da oligarquia e os interesses econômicos estrangeiros, especialmente estadunidenses. O genocídio guatemalteco atingiu o auge na década de 1980 e causou a morte e o desaparecimento de cerca de 200.000 pessoas. Após os Acordos de Paz de 1996, uma comissão interdiocesana tentou esclarecer as graves violações dos direitos humanos perpetuadas durante a guerra civil. Os resultados foram publicados em 
um relatório de quatro volumes: "Guatemala: nunca mas". O Bispo da Cidade da Guatemala, monsenhor Juan José Gerardi, que presidiu a comissão para a recuperação da memória histórica, foi assassinado dois dias depois da apresentação do relatório. No entanto, a aspiração à justiça e à recuperação da memória histórica continua animando o compromisso social de muitos guatemaltecos e muitas guatemaltecas, levando o país a alguns resultados importantes: em 2013, numa sentença de relevância histórica, o general Rios Montt foi condenado por genocídio e crimes contra a humanidade por um tribunal do seu próprio país. Além disso, a repressão cultural teve resultado parcial. Durante séculos, os povos indígenas praticaram múltiplas formas de resistência e reinvenção cultural e transmitiram testemunhos fundamentais anteriores à Conquista. Um exemplo é o Popol Wuj, o livro da história e da mitologia maia, salvo da Inquisição graças à transcrição em caracteres latinos por alguns estudiosos indígenas. E, de fato, alguns anos depois da transcrição, o bispo do Iucatão, Diego de Landa, teria queimado toneladas de livros escritos em caracteres maias. Hoje o Popol Wuj é considerado um dos textos mais antigos da história da humanidade e uma contribuição fundamental à literatura mundial.

A cultura maia, portanto, não é um achado arqueológico desenterrado de um passado perdido, mas uma realidade viva e em constante mudança, hoje como em suas origens, como demostra o próprio elemento linguístico: atualmente a família linguística maia é composta por trinta línguas, das quais apenas duas são línguas mortas e as outras continuam a ser usadas na comunicação diária. A arte é um dos campos em que a reinvenção cultural e linguística se revela com maior força. Um exemplo são as canções de Sara Curruchich, uma jovem compositora guatemalteca de origem maia kaqchikel. Seus textos adotam um registro plurilinguístico, que mistura espanhol e kaqchikel, para propor temas relacionados à história e à cultura maia, à defesa dos direitos das mulheres e dos povos originários. Sandy Hernandez, por outro lado, é uma atriz e ativista guatemalteca, arteterapeuta, autora e educadora teatral. Sua personagem clown, Piccoletta, aborda questões complexas como o genocídio e a resistência indígena com ironia refinada, na convicção de que a arte e o sorriso podem ser um instrumento de cura coletiva. 


\section{Uma pedagogia para a vida}

A filosofia da educação maia está fundamentada nos princípios da relacionalidade cada ser pode existir só em virtude da rede de relações que gera a sua vida - e da complementaridade - as diferentes manifestações do universo são essenciais umas às outras. É uma pedagogia que visa a plenitude e a realização integral de cada uma e cada um, em harmonia com as ligações cósmicas, familiares, comunitárias, intergeracionais, terrestres. A concepção da pessoa como unidade de corpo, mente, coração e espírito reflete estes princípios, todavia a relacionalidade não envolve apenas o plano humano, mas tem uma base terrestre e cósmica.

De fato, os coletivos vegetais, animais, minerais e humanos são expressão da mesma raiz vital, embora tenham qualidades e faculdades distintas. As múltiplas manifestações da totalidade originária são complementares e se apoiam mutuamente. "Dia e noite são uma bela expressão dessa complementaridade. É a coexistência harmoniosa entre os diferentes [...]. Ambos os estados cedem o passo um ao outro, esperam-se e unificam-se para a realização da vida" (Cochoy Alva et al, 2014,p. 92). A própria constituição do universo é fundada em redes de relações e grupos de afinidade, como as galáxias e o nosso sistema solar. "Sem o Pai Sol, a Mãe Terra não poderia existir; sem a galáxia, o Pai Sol não poderia existir; sem a vibração energética do Universo, as galáxias não poderiam existir” (Ibidem, p. 32).

A filosofia da educação maia, portanto, atribui igual dignidade a tudo o que existe, porque tudo o que existe é essencial para e na totalidade. As próprias partes do corpo e, principalmente, as mãos são sagradas, porque são expressão e canalização do universo. Assim o significado profundo da educação comunitária é guiar cada pessoa para se reconhecer como uma chispa do fogo cósmico, alimentar esse fogo e ajudar os outros a alimentá-lo.

Esta conexão profunda pode ser melhor compreendida considerando a cosmogonia maia e especialmente a árvore da vida. Para os maias, os quatro pontos cardeais são as principais referências na superfície da terra: toda prática diária, desde as práticas agrícolas até os rituais e as ofertas, é organizada de acordo com eles. O leste é a direção mais importante, sendo o lugar no qual o sol nasce. Os pontos cardeais estão relacionados ao centro, em que surge a árvore da vida, o Axis Mundi, identificado pela maioria dos autores com a ceiba 
pentranda. Esta árvore majestosa explicita a comunicação entre as três dimensões do universo: o seu tronco atravessa o mundo mediano, as raízes afundam no mundo subterrâneo e os ramos se estendem nas diferentes camadas do céu. Os três níveis não representam regiões distintas, mas dimensões vivas profundamente interrelacionadas.

A integração no universo é uma condição mas, ao mesmo tempo, uma busca: todas as manifestações materiais e energéticas se sincronizam permanentemente para gerar a harmonia. Para os seres humanos, assumir a orientação à conexão significa tentar a todo momento se familiarizar com a vida e seu ciclos, conformando todos os atos pessoais, coletivos e sociais à ordem cósmica.

\section{Interdependência geracional}

$\mathrm{Na}$ filosofia da educação maia a interdependência geracional tem um lugar central: as avós e os avôs são depositários dos saberes que as netas e os netos assimilam junto com o leite materno, aprendendo através da partilha e da escuta dos conselhos que recebem nas diferentes etapas da vida (Ibidem).

O Popol Wuj é o livro que contém a mitologia e a história do povo maia k’iche'. O título significa "O livro do conselho", "O livro do que é comum", "O livro do povo". Sam Colop, um dos estudiosos mais importantes do texto, devolveu o Popol Wuj à linguagem poética na qual foi escrito originariamente. Além disso, sua identificação no universo cultural e linguístico maia confere unicidade ao seu esforço de compreensão e interpretação do livro sagrado maia.

De acordo com ele, entre 1554 e 1558, três autores k'iche' transcreveram a versão logosilábica do Popol Wuj em caracteres latinos, salvando dessa forma o texto da Inquisição. No início do século XVIII, o documento foi encontrado e traduzido ao espanhol pelo padre Francisco Ximénez e, em seguida, foram redigidas outras traduções. No entanto, o livro originário não é o Popol Wuj completo que conhecemos hoje: este inclui uma parte histórica que estava acontecendo no momento em que o autores k'iche' escreviam e que está relacionada com a perseguição, a tortura e a imposição do cristianismo realizadas pelos 
conquistadores espanhóis, comandados por Pedro Alvarado. Na parte final do documento, os autores k'iche' se apresentam como “mães da palavra”, "pais da palavra”. Sem o seu valioso trabalho, hoje não disporíamos deste livro ou, na melhor das hipóteses, os estudiosos estariam tentando decifrá-lo.

O Popol Wuj é uma história-mito, a parte histórica e a parte mítica não são claramente distintas, há uma transição constante entre a mitologia e a história. Além disso, a narrativa não segue um procedimento linear: por exemplo, a história da criação humana, que abre o livro, é retomada depois de uma pausa prolongada dedicada à saga dos heróis gêmeos, com a criação de homens e mulheres de milho depois de duas tentativas erradas de criação de seres a partir da lama e da madeira. A saga dos heróis gêmeos, Hunahpu e Xbalanque, é uma das partes mais poéticas e densas de significados espirituais no interior do Popol Wuj. Os dois enfrentam no jogo de bola os senhores de Xibalba, o inframundo. O jogo se torna um terrível combate, no decorrer do qual os gêmeos superam algumas provas formidáveis graças aos seus prodígios. Finalmente, se entregam voluntariamente à morte, para serem ressuscitados e transformados em mendigos e poderem assim derrotar os senhores de Xibalba. Após estes eventos, Hunahpu e Xbalanque se convertem no sol e na lua e ascendem ao céu.

Este conto constitui um dos testemunhos mais importantes do jogo de bola, descrito também em esculturas e em vasos de cerâmica finamente pintados. Aliás, acredita-se que os campos do jogo de bola estavam colocados em um nível mais baixo, justamente em referência aos atos dos heróis gêmeos no inframundo. O jogo foi praticado por todos os povos mesoamericanos, a partir de 1400 a.C. Seu objetivo e duração, o modo como a bola podia ser tocada, o tamanho do campo e da bola e o número de jogadores mudavam consideravelmente nas diferentes versões. De todo modo, a forma mais comum previa que os jogadores tivessem que acertar a bola com os quadris, os joelhos ou os cotovelos, e que os pontos fossem totalizados quando a bola passasse por um anel de pedra colocado em uma extremidade do campo. O jogo possuía um profundo significado ritual, como demonstra o fato que muitas vezes terminava com um sacrifício humano (ainda não está claro se eram sacrificados os perdedores ou os vencedores). A bola simbolizava o movimento do sol e, portanto, tinha que estar sempre em movimento. No Popol Wuj conta-se que quando chega o momento de sua 
morte os progenitores se dirigem aos filhos, recomendando para não esquecê-los e não apagálos da memória. Na interdependência entre ancestrais e descendentes, idosos e jovens, de fato está garantida a transmissão do conhecimento como processo de evolução espiritual que, ao mesmo tempo, é um permanente retorno à origem.

\section{Interdependência entre as espécies}

A interdependência entre os seres humanos e os outros seres vivos é atestada na filosofia da educação maia na concepção do animal protetor que, determinado pelo dia do nascimento, fica intimamente ligado à pessoa ao longo da vida toda.

Nahual, nahualli ou nagual é a palavra da língua nahuatl que, no contexto mesoamericano, identifica este alter ego relacionado ao mundo natural. De acordo com Rigoberta Menchú, a ativista maia vencedora do Prêmio Nobel pela Paz, em 1992, o nahual explicita a conexão profunda entre os seres humanos e a natureza: não há separação clara entre os animais e os seres humanos, porque tudo o que existe na terra tem relação com os seres humanos e contribui para a sua existência. O termo, todavia, pode indicar também uma pessoa que tem o poder de mudar de forma e se tornar um animal. Deste segundo significado nos oferece uma linda representação o Prêmio Nobel pela Literatura, Miguel Ángel Asturias, no seu livro "Hombres de mais", ao descrever um ser que tem a faculdade de ser homem e animal, curandeiro e cervo. No decorrer da narração, o cervo é alvejado e seu corpo fica no lugar onde a morte o encontrou, mas também o curandeiro morre deixando seu corpo onde tinha acontecido a metamorfose em cervo.

\section{Interdependência cósmica}


"O céu estrelado dentro de nós" é uma expressão da comunidade filosófica feminina italiana Diotima, que retoma e subverte uma frase muito conhecida de Kant: "Duas coisas me enchem o espírito de admiração e de reverência sempre nova e crescente, quanto mais frequentemente e longamente o pensamento nelas se detém: o céu estrelado acima de mim e a lei moral dentro de mim". A expressão de Diotima reune o que Kant separa e mostra que a ordem da realidade está dentro de nós como fora. Essa afirmação pode nos ajudar a compreender a importância do estudo do céu para os Maias, como tentativa constante de decodificar as leis profundas do universo para entrar em sintonia com elas.

Durante séculos, os Maias dedicaram uma atenção sistemática à astronomia e às suas repercussões nos eventos pessoais e coletivos (como as guerras e as práticas agrícolas). Graças a refinados estudos matemáticos e à noção do zero, realizaram cálculos muito complexos; e mesmo podendo usar somente a observação a olho nu, chegaram a conhecer o comportamento dos corpos celestes (principalmente do sol, da lua e do planeta Vênus). Construíram um calendário solar tão preciso quanto o que usamos hoje e previram fenômenos astronômicos muito distantes no tempo.

A competência astronômica maia é revelada pelo código de Dresden, redigido na escrita logosilábica e assim chamado pela cidade em que foi reencontrado. Trata-se de um dos manuscritos mais antigos do continente americano, que escapou da fogueira da Inquisição junto com outros três. O conteúdo que até agora foi possível decifrar inclui tabelas lunares que descrevem a influência das fases da lua na vida coletiva, por exemplo nos nascimentos e nas mortes; o ciclo do planeta Vênus e as relativas indicações de caráter bélico; páginas dedicadas à divindade da chuva, Chac, sumamente importante porque ligada à agricultura; previsões de eclipses (os Maias lograram entender que há uma grande chance de que um eclipse solar ou lunar ocorra após respectivamente 177 ou 148 dias lunares desde o último eclipse); rituais, cerimônias e profecias. Acredita-se que o código de Dresden foi elaborado pelo menos por cinco escribas. O refinamento da fabricação nos permite deduzir sua importância religiosa e cultural.

Também a arquitetura estava associada ao estudo do céu e muitos edifícios construídos pelos Maias eram observatórios astronômicos. Na cidade mexicana de Chichén Itzá, o templo 
dedicado ao deus Kukulcán (a Serpente Emplumada) reproduz em sua estrutura o calendário solar usado pelos Maias. O edifício é formado por uma série de terraços quadrangulares de 24 metros de altura e culmina com um templo quadrangular de seis metros. Em cada um dos quatro lados há uma escadaria de 91 degraus. Somando os degraus e o templo central, obtemos o número 365, ou seja, o número de dias que compunha o calendário solar usado pelos Maias. Além disso, ao pé da escada norte encontram-se esculpidas duas cabeças de cobra. Durante os equinócios de primavera e outono, o sol da tarde bate no ângulo noroeste da pirâmide, projetando sombras triangulares que se juntam com uma das cabeças esculpidas completando a imagem de uma serpente emplumada, que rasteja ao longo da pirâmide na direção do céu.

A observação do céu tinha múltiplos efeitos na vida coletiva, sobretudo através dos calendários. Os povos mesoamericanos compartilhavam o uso de dois calendários, que eram chamados de maneira diferente, mas funcionavam da mesma maneira. Um calendário ritual e adivinhatório consistia em 260 dias (13 meses de 20 dias, ou 20 meses de 13 dias, dependendo das culturas). No calendário ritual, cada dia correspondia a um nome e um número. Os nomes dos recém-nascidos eram escolhidos de acordo com esta associação, com base na qual era possível também antecipar seu destino. Por outro lado, o calendário solar de 365 dias incluía 18 meses de 20 dias cada um mais um apêndice de cinco dias, e era uma referência essencial para a realização das atividades agrícolas. O comprimento divergente dos dois calendários determinara que certa combinação de datas se repetisse a cada 52 anos. Este período de tempo, portanto, tinha um significado fundamental porque indicava a conclusão de um ciclo e na vida de uma pessoa marcava a conquista da maturidade.

Os Maias elaboraram também uma forma de medição do tempo conhecida como Contagem Longa. Neste calendário, a unidade mínima é o dia, k’in; vinte dias originam um mês, winal; 18 winal formam um ano de 360 dias, o tun; 20 tun produzem um k'atun (7200 dias, quase 20 anos do nosso calendário); 20 k'atun formam um b'ak'tun (144.000 dias, cerca de 400 anos) e assim por diante. Trata-se de um cálculo com base vigesimal que compreende um tempo muito longo. Este cálculo era usado nas inscrições e permitiu aos Maias identificar uma data-era, que para nós corresponde ao 11 de agosto de 3114 a.C., em que colocar o 
começo de sua história. De acordo com a Contagem Longa, no dia 21 de dezembro de 2012, o décimo terceiro b'ak'tun se concluiu. É, portanto, uma data importante, que indica o fim de um ciclo e o início de outro.

Para os Maias, os seres humanos tinham que colaborar com as divindades para manter o tempo e a ordem cósmica e nessa ótica realizavam rituais e sacrifícios. Matemática, astronomia, arquitetura e medição do tempo através de calendários, portanto, eram campos de estudo profundamente interconectados, cujo sentido era o de compreender o universo para conformar a vida na terra.

\section{Conclusões: questionando o ser, o viver, o poder e o saber a partir da filosofia da educação maia}

A adesão a uma abordagem intercultural crítica - uma abordagem capaz não somente de valorizar a disposição individual à relação, mas, também, de reconhecer e desconstruir as estruturas de poder, os dispositivos coloniais e o uso instrumental da diferença cultural e epistémica (Walsh, 2009) - exige um questionamento da própria constituição do conhecimento pedagógico e de sua narração histórica.

De fato, longe de ser neutro, o que é transmitido como História da Pedagogia é um saber excludente, que seleciona apenas algumas tradições de pensamento designadas como origem e fontes de legitimação da civilização ocidental. Este questionamento é essencial também para promover uma concepção mais ampla de sustentabilidade, com base na superação do paradigma hegemônico moderno-colonial-masculino sobre as ciências e as disciplinas, e na valorização de epistemologias e racionalidades outras (Muraca, Cima, Alga, 2014).

Neste artigo tive a pretensão de ler os mundos das outras e dos outros, tornando-me uma pesquisadora colonizadora? Espero que não. Aliás, o desejo foi, em virtude de uma profunda gratidão pelas aprendizagens que pude amadurecer até aqui graças a movimentos, comunidades, líderes e intelectuais Maias, tentar desmentir a já insustentável presunção de que a filosofia da educação seja um produto ocidental. O sentido dessa operação é a 
ampliação de nossos horizontes epistemológicos e teóricos em favor da vida. Assim os limitados aspectos que explorei com relação à filosofia da educação Maia podem proporcionar significativos elementos para superar a disjunção, que historicamente justificou a exploração de seres humanos por parte de outros seres humanos e a exclusão da grande maioria da humanidade de cada tipo de direito; e o antropocentrismo, que, através da imposição de uma hierarquia, promoveu o domínio do homem sobre os outros seres vivos e a exploração indiscriminada do planeta (Contini, 2009); e para favorecer uma consciência positiva da vulnerabilidade e da necessidade dos outros (Praetorius, 2011) que, a partir do reconhecimento dos múltiplos laços que conectam cada homem e cada mulher ao mundo, permita compreender a liberdade não como autossuficiência, independência do corpo e isolamento dos outros, mas em termos constitutivamente relacionais (Tommasi, 1995).

\section{REFERÊNCIAS}

ASTURIAS, M. Á. Uomini di mais. Milano: Rizzoli, 1968.

CASTRO-GÓMEZ, S. La hybris del punto cero: ciencia, raza e ilustración en la Nueva Granada (1750-1816), Bogotá: Editorial Pontificia UniversidadJaveriana, 2005.

COCHOY ALVA, M. F. RaxalajMayab'K'Aslemalil. Cosmovisión maya, plenitud de la vida. Ciudad de Guatemala: Programa de las Naciones Unidas para el Desarrollo, 2014.

COLOP, S. Popol Wuj. Ciudad de Guatemala: F\&G editores, 2011.

CONTINI, M. Elogio dello scarto e della resistenza. Bologna: CLUEB, 2009.

DIOTIMA. Il cielo stellato dentro di noi. L'ordine simbolico della madre. Napoli: Liguori, 1992.

FRABBONI, F. Una scienza maggiorenne. In: FRABBONI, F.; Wallnöfer (orgs). La pedagogia tra sfide e utopie. Milano: Francoangeli, 2009, p. 15-35.

FREIRE, P. Pedagogia do oprimido. Rio de Janeiro: Paz e Terra, 1987.

MENCHÚ, R.; BURGOS, E. Mi chiamo RigobertaMenchú. Firenze-Milano: Giunti, 2006. MIGNOLO, W. D. The geopolitics of knowledge and the colonial difference. South Atlantic Quarterly, 101.1, p. 57-96, 2002. 
MURACA, M.; CIMA, R;. ALGA, L. Anatomia dos olhares na pesquisa científica. Em aberto, v. 27, n. 91, P. 111-122, 2014.

PRAETORIUS, I. Penelope a Davos. Idee femministe per un'economia globale. I quaderni di via dogana, Milano, 2011.

PROYECTO INTERDIOCESANO RECUPERACIÓN DE LA MEMORIA HISTÓRICA, Guatemala nunca mas. Ciudad de Guatemala: Oficina de Derechos Humanos del Arzobispado de Guatemala, 1998.

TODOROV, T. La conquista de la América. El problema del otro. Ciudade de Mexico: Siglo XXI editores, 1987.

TOMMASI, W. Il lavoro del servo. In: Diotima. Oltre l'uguaglianza. Le radici femminili dell'autorità. Napoli: Liguori, 1995.

WALSH, C. Sono possibili scienze sociali/culturali altre? Riflessioni sulle epistemologie decoloniali. In: ASCIONE, G. (org). America latina e modernità. L'opzione decoloniale: saggi scelti. Salerno: edizioni arcoiris, 2014.

. Interculturalidad y (de)colonialidad. Perspectivas críticas y políticas, trabalho apresentado ao XII Congreso ARIC-Associacion Internacional pour la Recherche Interculturelle, Florianópolis, Universidade Federal de Santa Catarina, 2009.

\footnotetext{
${ }^{\text {i }}$ Quero dedicar este artigo à memória de Juana Ramírez Santiago, liderança da Rede de Mulheres Maia Ixiles e defensora dos direitos humanos, que foi assassinada dia 21 de setembro de 2018, no município de Nebaj, na Guatemala.

ii Università di Verona, Istituto Universitario Giorgio Pratesi. (mariateresa85muraca@gmail.com)
} 